\title{
Cu/CNF Nanocomposite Processed by Novel Salt Decomposition Method
}

\author{
Cécile Vincent $^{1}$, Jean-Marc Heintz ${ }^{1}$, Jean-Francois Silvain ${ }^{1}$, Namas Chandra ${ }^{2}$ \\ ${ }^{1}$ ICMCB, CNRS, Pessac, France \\ ${ }^{2}$ College of Engineering, University of Nebraska, Lincoln, United States \\ E-mail:vincent@icmcb-bordeaux.cnrs.fr \\ Received August 5, 2011; revised September 10, 2011; accepted September 20, 2011
}

\begin{abstract}
Thermal dissipation in power electronic devices can be improved through the elaboration of a new generation of layered heat sinks based on copper $(\mathrm{Cu})$-carbon nanofibers $(\mathrm{CNF})$ composites. Though the high theoretical thermal conductivity of $\mathrm{CNF}(1200 \mathrm{~W} / \mathrm{mK})$ no $\mathrm{Cu}-\mathrm{CNF}$ composites with enhanced thermal properties are available. Indeed conventional compositing processes do not allow neither a good dispersion of the nano-reinforcements nor a control of the nanofiber-matrix interface which is not suitable for efficient heat transfers. In this paper, a process based on CNF coating with $\mathrm{Cu}$ followed by uniaxial hot pressing in described. It is shown that under proper experimental conditions the salt decomposition coating method is capable of achieving the desired high thermal conductivity values $(>400 \mathrm{~W} / \mathrm{mK})$ thanks to a good dispersion of the $\mathrm{CNF}$, low porosity content and the control of $\mathrm{Cu}-\mathrm{CNF}$ interfaces.
\end{abstract}

Keywords: Carbon Nanofibers, Metal Matrix Composite, Powder Processing, Thermal Properties

\section{Introduction}

Performance of new power electronic devices is currently limited by packaging of modules. Indeed electronic properties of multichip modules can not be fully exploited due to problems of heat dissipation. More and more powerful silicon or silicon carbide chips produce more and more heat that leads to early failure of the different components. There is thus, a strong need for the development of novel heat dissipation materials. They must combine high thermal conductivity and a coefficient of thermal expansion (CTE) compatible with that of the ceramic materials (alumina, silicon nitride or aluminum nitride) on which they are brazed. Knowing the CTE of those ceramics are lower than $8 \mathrm{ppm} / \mathrm{K}$, the use of copper as heat sink with a CTE of $17 \mathrm{ppm} / \mathrm{K}$ is not acceptable from thermal stresses point of view. The CTE of copper can be reproductively reduced (in a plane) to $10 \mathrm{ppm} / \mathrm{K}$ by adding carbon fibers (CF) having an axial CTE close to zero. This decrease in heat sink CTE allows a diminution of thermomechanical stresses in power modules and associated phenomena like delamination at solder joints, failure of ceramic that improves the reliability of these modules.

Further, the high axial thermal conductivity of carbon fibers $(>400 \mathrm{~W} / \mathrm{mK})$ makes potentially carbon-fibers reinforced copper an ideal candidate for the realization of heat sink materials $[1,2]$. In fact these composites are processed by powder metallurgy (PM), consisting in a simple mechanical mixing of $\mathrm{CF}$ and copper powder, that does not allow the formation of chemical interfaces between carbon fibers and copper [3]. Consequently, heat transfers between CF and the matrix are not effective and thermal properties of $\mathrm{Cu}-\mathrm{CF}$ composites are not as high as expected $(320 \mathrm{~W} / \mathrm{mK}$ in plane for $\mathrm{Cu}+40$ vol. $\% \mathrm{CF}$ with $\mathrm{k}_{\mathrm{CF}}=540 \mathrm{~W} / \mathrm{mK}$ ) that is not suitable for thermal management of power electronic modules.

A clever design of the heat sink should be a multilayer material. A bulk part, at the bottom, exhibiting a low CTE to limit thermomechanical strains and an upper thin layer in contact with the heat source, i. e. the chip, with a high thermal conductivity to spread the heat effectively in a plane is potentially a good design to enhance lifetime of modules.

The goal of this work is to process copper-carbon nanofibers composite materials with enhanced thermal conductivity compared to copper without significantly decreasing thermal expansion values, which will be achieved by the bulk layer made of $\mathrm{Cu}$-CF material. No problem of interfaces between the different layers can 
appear as they are all based on copper matrix. Vapour grown carbon nanofibers (VGCNF or CNF) with a theoretical thermal conductivity close to $1200 \mathrm{~W} / \mathrm{mK}$ (axial) are an ideal reinforcement based on cost and performance [4]. Due to the high aspect ratio of CNF (around 100), the calculated percolation threshold is estimated to be smaller than $10 \%$ in volume fraction.

As a consequence the composite to be processed in this study will contain a volume fraction of CNF lower than $10 \%$ to avoid problems of dispersion and homogeneity and CNF-CNF contacts. The increase of copper conductivity will be limited by the low volume fraction of CNF added in the matrix and will not exceed 440 $\mathrm{W} / \mathrm{mK}$ according to the rule of mixture. This value can be achieved if the reinforcement is fully dispersed in the matrix, if the porosity content is close to zero and if $\mathrm{CNF}-\mathrm{Cu}$ contacts are heat conductive.

Amongst many possible processing methods, powder metallurgy easily stands out since the process overcomes the difficulty induced by the nonwetting nature of carbon in liquid copper [5-7]. The most important problem in the processing relates to obtaining the desired dispersion of the carbon nanofibers within the metal matrix.

Two parameters limit the success of this objective:

- The carbon nanofibers are chemically inert and do not react with copper.

- During the densification process, homogeneous distribution of CNF does not occur due to (1) small size of the nanofibers compared to the grain size of the copper matrix, and (2) do not allow a deagglomeration of carbon nanofibers with a simple mechanical mixing.

In a previous work [8] it was shown that a new method based on salt decomposition was efficient to reach thermal conductivities superior to that of copper compared to classical methods like powder metallurgy or electroless plating. In this paper, the salt decomposition method, as known as molecular level mixing [9] is detailed. A chemical treatment has been first investigated to create nucleation sites on the CNF surface and enhance matrix-reinforcement link. A metallic salt was selected among two (copper chloride and nitrate) and different experimental conditions (solvent, mixing, heat treatments) were optimized.

In section 3 , we present the microstructural characteristics and the thermal properties of samples at different stages of the method and correlate the processing conditions to the properties of the materials.

\section{Experimental}

\subsection{Coating Process}

The aim of this process is to coat individualized CNF with homogeneous copper thin film of desired thickness. Vapor Grown Carbon NanoFibers (Figure 1) that will be named CNF from Showa Denko KK were used (Table 1).

The chemical coating process consists in four steps:

1) The dispersion of CNF in a solvent using a high energetic ultrasonic treatment. Three solvent compositions have been tested (Pure ethanol, ethanol + water (1:1) and ethanol + water $(1: 3))$. The boiling point of ethanol is $79^{\circ} \mathrm{C}$, and that of water is $100^{\circ} \mathrm{C}$ at atmospheric pressure.

2) The choice of copper salt and its concentration. Two salts have been tested (copper chloride and copper nitrate). For a given concentration $(100 \mathrm{~g} / \mathrm{L})$, each salt has been dissolved in the three solvents. For the best "solvent-salt" couple the effect of the salt concentration on the morphology of the coating has been analyzed after the evaporation of the solvent $\left(80^{\circ} \mathrm{C}\right.$ in air) and adapted annealing treatment. The two different annealing treatments are analyzed in step 3 .

3) After the solvent evaporation step two main annealing treatments have been performed. In the first one the dry copper nitrate-CNF powder is treated at $400^{\circ} \mathrm{C}$ in air during 2 hours and then reduced at $400^{\circ} \mathrm{C}$ during 1 hour under reducing atmosphere $\left(\mathrm{Ar} / 5 \% \mathrm{H}_{2}\right)$. In the second one dry copper nitrate-CNF powder is directly treated at $400^{\circ} \mathrm{C}$ during 2 hours under reducing atmosphere $\left(\mathrm{Ar} / 5 \% \mathrm{H}_{2}\right)$. The finally treated $\mathrm{Cu} / \mathrm{CNF}$ powder is observed by SEM in order to determine the morphology (thickness, grain size, homogeneity) of the $\mathrm{Cu}$ coating and the distribution of the CNF.

4) Finally the treated $\mathrm{Cu} / \mathrm{CNF}$ powder is densified at $650^{\circ} \mathrm{C}$ during $20 \mathrm{~min}$, a $50 \mathrm{MPa}$ uniaxial pressure under reducing atmosphere $\left(\mathrm{Ar} / 5 \% \mathrm{H}_{2}\right)$. TEM analyses have been performed on densified $\mathrm{Cu} / \mathrm{CNF}$ composite in order to reveal the distribution and the $\mathrm{Cu} / \mathrm{CNF}$ interfacial properties.

Table 1. Basic physical properties of carbon nanofibers.

\begin{tabular}{cccc}
\hline Size & Density & $\begin{array}{c}\text { Thermal } \\
\text { conductivity }\end{array}$ & CTE \\
\hline $\begin{array}{c}150 \mathrm{~nm} \text { in } \\
\text { diameter }>10 \mu \mathrm{m} \\
\text { length }\end{array}$ & 2.2 & $\begin{array}{c}1200 \mathrm{~W} / \mathrm{mK} \\
\text { (axial) } 20 \mathrm{~W} / \mathrm{mK} \\
\text { (transverse) }\end{array}$ & $\begin{array}{c}0 \mathrm{ppm} / \mathrm{K} \text { (axial) } \\
12 \mathrm{ppm} / \mathrm{K} \\
\text { (transverse) }\end{array}$ \\
\hline
\end{tabular}

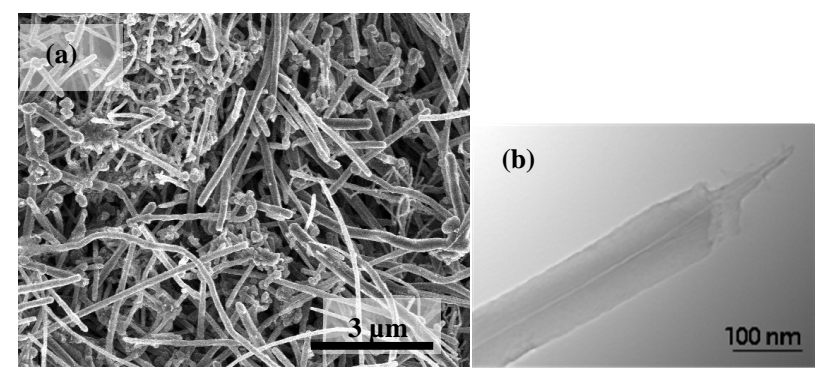

Figure 1. (a) SE micrograph of CNF; (b) TEM image of CNF. 


\subsection{Characterizations}

Microstructure: Microstructures of the composites powders were characterized in scanning electron microscopy with a Jeol 840. No metallization treatment is required as the samples are electrically conductive. Densified samples were observed in transmission electron microscopy with a Jeol 200CX.

Themal characterizations: The thermal conductivity was measured using flash laser apparatus [10,11], Netzsch LFA 457. The specimens are cylindrical $(6 \mathrm{~mm}$ of diameter and $3 \mathrm{~mm}$ of height) due to the sample geometry required by the laser flash apparatus. Therefore can be measured only in the direction parallel to the densification axis. It should be noted that the thermal properties are likely to be isotropic due to the random orientation of the anistropic CNF $(\mathrm{k}=1200 \mathrm{~W} / \mathrm{mK}$ in parallel axis and $\mathrm{k}=20 \mathrm{~W} / \mathrm{mK}$ in perpendicular axis).

Porosity measurements: The volume fraction of porosity was determined by two methods.

In the first method, the apparent density $\rho 1$ of the sample is (1) $\rho_{1}=m / V$, where $m$ is the mass and V is the volume. In the second method, the relative density of the sample is calculated according to Archimedes principle. If $\left(\mathbf{m}_{1}\right)$ is the weight in air and $\left(\mathbf{m}_{2}\right)$ is the weight in water, the density $\rho_{2}$ is given by

(2) $\rho_{2}=\rho \mathrm{H}_{2} \mathrm{O} \cdot \mathrm{m}_{1} /\left(\mathbf{m}_{1}-\mathbf{m}_{2}\right)$

In this case, $\mathbf{m}_{2}$ is measured instantaneously (as soon as the sample is lowered into the water) to assure that both open and closed porosity volume fractions are accounted for. The density of water is considered to be equal to 1 at room temperature.

Porosity volume fraction can then be calculated using

(3) vol. $\%=\left(1-\rho_{\text {exp }}\right) / \rho_{\text {th }} \times 100$

$\rho_{\text {th }}$ is the density of the composite calculated according to the rule of mixture and based on the densities of copper $8.96 \mathrm{~g} / \mathrm{cm}^{3}$ and CNF $2.2 \mathrm{~g} / \mathrm{cm}^{3}$. $\rho_{\text {exp }}$ is the average of $\rho_{1}$ and $\rho_{2}$. This method is typically used to average the lower density (overestimation of the volume of the sample) in the first case, and higher density (overestimation of $\mathrm{m}_{2}$ ) in the second case.

Densification of the $\mathrm{Cu} / \mathrm{CNF}$ composite: As already stated the densification process involving uniaxial hot pressing was used. The samples were pressed at $650^{\circ} \mathrm{C}$ under $50 \mathrm{MPa}$ for 20 minutes with a heating rate in the range of $25^{\circ} \mathrm{C} / \mathrm{min}$. The temperature was measured by inserting a thermocouple inside the graphite mold, and the measurement was used to control the temperature within a range of $\pm 10^{\circ} \mathrm{C}$. Sintering was performed under reducing atmosphere $\left(\mathrm{Ar} / 5 \% \mathrm{H}_{2}\right)$ in order to prevent oxidation of the nano copper composite powder during the heating cycle.

\section{Results and Discussions}

\subsection{Effect of the Solvent}

Table 2 shows the evolution of the copper grain size (after the evaporation of the solvent and the two steps of heat treatment) for the copper nitrate salt. It is clear from this table that for pure ethanol solvent the smallest $\mathrm{Cu}$ grain size associated with homogeneously CNF coating is observed. Therefore, in order to minimize the number of experiments, this solvent is used for all further experiments whatever the copper salt used.

It has to be mentioned that for the other tested salt (copper chloride) the quasi absence of coating onto CNF do not allow us to determine any grain size variation with the solvents [11].

\subsection{Ultrasonication of CNF in Ethanol}

It has been shown by XPS analysis that after a sonication treatment in ethanol, reactive sites in the form of oxygenated groups $(\mathrm{C}=\mathrm{O}, \mathrm{COOH})$ are attached on the $\mathrm{CNF}$ surface [12] and furthermore act as nucleation site for metal growth. The time of sonication was adjusted so that a stable suspension of CNF is obtained without damaging the desired CNF characteristic (length ...). The XPS quantitative analysis of the oxygen content showed that a time of sonication equal to one hour was enough to create $\mathrm{O}$ groups on the $\mathrm{CNF}$ without damaging their structure. Therefore, the duration of one hour was chosen for the elaboration of the CNF suspension and the CNF surface functionalization.

\subsection{Salt Choice and Concentration}

Effect of the nature of the salt: The two salts (copper nitrate: $\mathrm{Cu}\left(\mathrm{NO}_{3}\right)_{2}, 3 \mathrm{H}_{2} \mathrm{O}$ and Chloride: $\mathrm{CuCl}_{2}$ ) have been chosen due to their good solubility properties in the three tested solvents. Once the CNF are dispersed in ethanol (the solvent chosen see section 3.1), for the $100 \mathrm{~g} / \mathrm{L}$ salt concentration, the two metallic salts are added to the two suspensions and mechanically stirred at $80^{\circ} \mathrm{C}$ until complete evaporation of the solvent. Figures 2(a) and (b)

Table 2. Cu grains size in $\mathrm{Cu} / \mathrm{CNF}$ composite in function of the chemical nature of solvent.

\begin{tabular}{|c|c|c|c|}
\hline Size & Density & Thermal conductivity & CTE \\
\hline $\begin{array}{c}150 \mathrm{~nm} \text { in diameter } \\
>10 \mu \mathrm{m} \text { length }\end{array}$ & 2.2 & $\begin{array}{c}1200 \mathrm{~W} / \mathrm{mK} \text { (axial) } \\
20 \mathrm{~W} / \mathrm{mK} \text { (transverse) }\end{array}$ & $\begin{array}{c}0 \mathrm{ppm} / \mathrm{K} \text { (axial) } \\
12 \mathrm{ppm} / \mathrm{K} \text { (transverse) }\end{array}$ \\
\hline
\end{tabular}


show SE micrographs of the CNF coated with the copper nitrate and copper chloride salts respectively. At that stage, for the copper nitrate salt (Figure 2(a)), CNF cannot be observed anymore after the final annealing process. It is not a proof that the CNF are individually coated but just that all the $\mathrm{CNF}$ are embedded inside the copper matrix leading to formation of nanocomposite powder.

It can be observed in Figure 2(b) that the CNF are not coated with copper when $\mathrm{CuCl}_{2}$ is used and that copper grains of close or less than 1 micron in diameter are observed on the side of the CNF. Therefore this salt and process can be used to uniformely disperse micronic or submicronic copper grain with CNF but cannot be used to uniformely coat CNF with copper. Based on this results further experiments will only be conducted with the copper nitrate salt.

Figure 3 shows on a simplified scheme the evolution of the $\mathrm{Cu}$ network on $\mathrm{CNF}$ during the deposition and calcinations steps. First, the sonication of the CNF brings oxygen, mainly in the form of $\mathrm{OH}$ groups, at their surface. Then after evaporation of the solvent, copper species in the form of $-\mathrm{Cu}-\mathrm{O}-\mathrm{NO}_{\mathrm{x}}$ or $-\mathrm{Cu}-\mathrm{Cl}_{2}$ are chemically linked to the oxygenated groups. The step of calcination with departure of $\mathrm{N}$ and $\mathrm{Cl}$ based groups leads to the formation of a O-Cu-O network in the case of nitrate and does not allow the formation of this type of network when copper chloride is used. In fact, $\mathrm{Cl}$ is monovalent and is linked only with copper. The rupture of $\mathrm{Cu}-\mathrm{Cl}$ bonds with temperature does not lead to the formation of a O-Cu-O network due to the absence of oxygenated
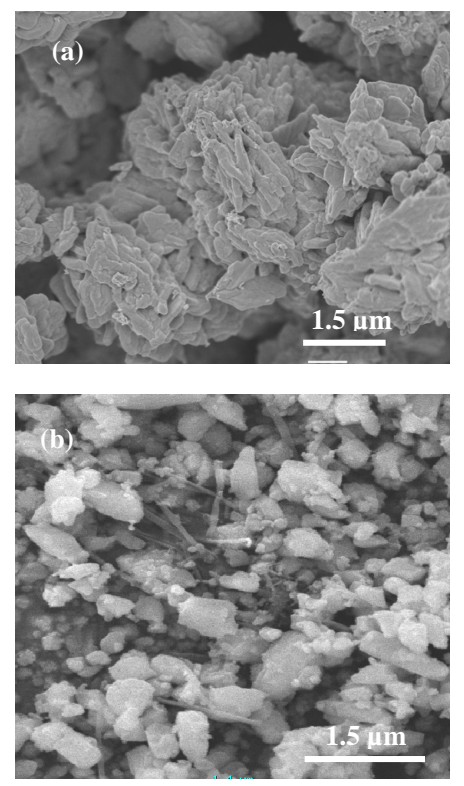

Figure 2. SEM micrograph of composite powder after annealing treatments (a) From $\mathrm{Cu}\left(\mathrm{NO}_{3}\right)_{2} \cdot 3 \mathrm{H}_{2} \mathrm{O}$; (b) From $\mathrm{CuCl}_{2}$. groups on $\mathrm{Cl}$ atoms. Furthermore, the thermal decomposition of $\mathrm{CuCl}_{2}$ on the CNF occurs mainly in the form of a sublimation of the chloride with breaking of (CNF-)O-Cu bonds. After calcination step the CNF remain uncovered by copper when $\mathrm{CuCl}_{2}$ salt is used.

In the case of copper nitrate, the phenomenon of poly condensation occurs, as in sol-gel process for example. The departure of $\mathrm{H}_{2} \mathrm{O}$ and $\mathrm{NO}_{\mathrm{x}}$ groups is immediately followed by a rearrangement of the chemical bonds and a tridimensionnal $\mathrm{O}-\mathrm{Cu}-\mathrm{O}-\mathrm{Cu}$ network is formed, leading to a thick coating of the CNF. The oxygen is finally eliminated of the coating during the step of reduction.

Effect of the concentration of the $\mathrm{Cu}$ nitrate salt: Four salt concentrations of $\mathrm{Cu}$ nitrate in pure ethanol have been tested: 50, 100, 133 and 200 g/L. Figure 4 shows the evolution of the $\mathrm{CNF} / \mathrm{Cu}$ nanocomposite microstructure with the salt concentration. It has to be noticed first that for the highest concentration $(200 \mathrm{~g} / \mathrm{L})$ a gel is formed and cannot be properly dried. Therefore the evaporation step is difficult to achieve and leads to a viscous solid which cannot be observed by SEM. After the evaporation of the ethanol solvant, a blue solid characteristic to $\mathrm{Cu}$ nitrate can be obtained for the three other salt concentrations $(50,100$ and $133 \mathrm{~g} / \mathrm{L})$. For the same copper nitrate concentration, it can be observed in Figure 4 that when the salt concentration decreases the copper grain size decreases (Table 3). Until a gel is not formed, metallic copper grain size can be easily monitored with the salt concentration going from submicronic grain to micronic one. For thermal application, higher density of grain boundaries in metal matrix composite materials is usually linked with a degradation of composite thermal properties. Therefore for identical coating behaviour larger grain size has to be chosen (100 and $133 \mathrm{~g} / \mathrm{L})$. For an economical point of view, we chose the $133 \mathrm{~g} / \mathrm{L}$ concentration of $\mathrm{Cu}$ nitrate in ethanol solvent for all the coating process.

\subsection{Annealing Treatment}

Annealing treatments of the mixture of CNF inside ethanol solvent using copper nitrate salt with concentration of $133 \mathrm{~g} / \mathrm{L}$ have been performed in order to transform $\mathrm{Cu}-\mathrm{O}-\mathrm{N}$ species into pure copper. As mentioned previously, two types of treatments have been performed. The first one (a) is a two steps process (calcination under air followed by a calcination under $\mathrm{Ar} / \mathrm{H}_{2}$ ) and the second one (b) is a one step process (calcination under $\mathrm{Ar} / \mathrm{H}_{2}$ ). The effect of the process on the nucleation and growth and on the morphology of the coating is evaluated below.

(a): Calcination of $\mathrm{Cu}_{2}(\mathrm{OH})_{3}\left(\mathrm{NO}_{3}\right)$ at $400^{\circ} \mathrm{C}$ (air) + heat treatment at $400^{\circ} \mathrm{C}\left(\mathrm{Ar} / \mathrm{H}_{2}\right)$ Chemical reactions oc- 


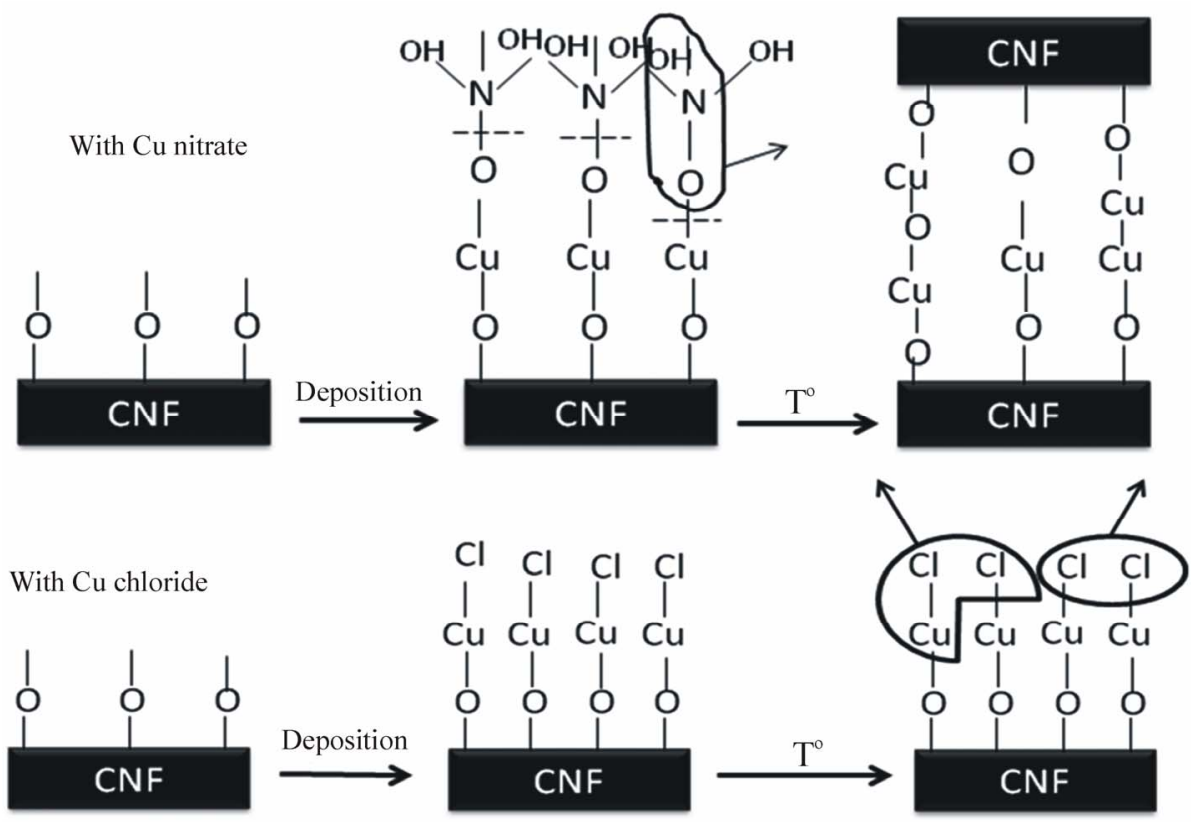

Figure 3. Mechanism of formation and evolution of the $\mathrm{C}-\mathrm{Cu}$ network along the different steps of the process for the two salts: $\mathrm{Cu}\left(\mathrm{NO}_{3}\right)_{2} \cdot 3 \mathrm{H}_{2} \mathrm{O}$ and $\mathrm{CuCl}_{2}$.
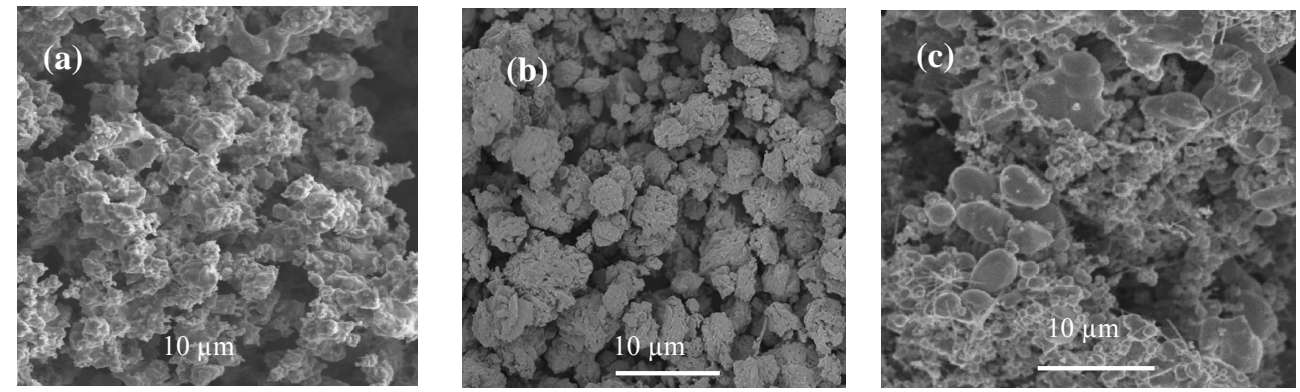

Figure 4. SE micrographs of $\mathrm{Cu} / \mathrm{CNF}$ composite for different concentrations of $\mathrm{Cu}$ nitrate in ethanol (a) $50 \mathrm{~g} / \mathrm{L}$; (b) $100 \mathrm{~g} / \mathrm{L}$; (c) $133 \mathrm{~g} / \mathrm{L}$.

Table 3. Average Cu grain size after evaporation of the solvent and heat treatment for $\mathrm{Cu}$ nitrate in ethanol.

\begin{tabular}{cc}
\hline Salt concentration $(\mathrm{g} / \mathrm{L})$ & Cu mean grain size $(\boldsymbol{\mu m})$ \\
\hline 50 & 1 \\
100 & 6 \\
133 & 6 \\
200 & $/$ \\
\hline
\end{tabular}

curring during the heating step can be summed up as follows:

$$
\begin{aligned}
& \quad \mathrm{Cu}_{2}(\mathrm{OH})_{3}\left(\mathrm{NO}_{3}\right)(\mathrm{s}) \rightarrow 2 \mathrm{Cu}(\mathrm{OH})_{2}(\mathrm{~s})+\mathrm{NO}_{2}(\mathrm{~g}) \rightarrow \mathrm{CuO} \\
& +\mathrm{H}_{2} \mathrm{O}(\mathrm{g}) \\
& \mathrm{At} \mathrm{T}=423 \mathrm{~K} \mathrm{Cu}(\mathrm{OH})_{2}(\mathrm{~s}) \rightarrow \mathrm{CuO}(\mathrm{s})+\mathrm{H}_{2} \mathrm{O}(\mathrm{g}) \\
& \mathrm{Or} \mathrm{Cu}_{2}(\mathrm{OH})_{3}\left(\mathrm{NO}_{3}\right)(\mathrm{s}) \rightarrow 2 \mathrm{CuO}+\mathrm{HNO}_{3}+\mathrm{H}_{2} \mathrm{O} \text { as } \\
& \text { studied by Morozov et al. }[13] .
\end{aligned}
$$

Figure 5 shows a thermogravimetric analysis in air of
$\mathrm{Cu}_{2}(\mathrm{OH})_{3}\left(\mathrm{NO}_{3}\right) / \mathrm{CNF}$ powders between room temperature and $500^{\circ} \mathrm{C}$. It is clearly shown that the thermal decomposition of the $\mathrm{Cu}_{2}(\mathrm{OH})_{3}\left(\mathrm{NO}_{3}\right)$ compound is achieved at $400^{\circ} \mathrm{C}$. Mass spectrometer analyses were combined to the TGA analysis but the simultaneous decomposition of many species did not give significant results. The X-Ray Diffraction pattern (Figure 6) also shows that, after the heat treatment at $400^{\circ} \mathrm{C}$ in air, the $\mathrm{Cu}_{2}(\mathrm{OH})_{3}\left(\mathrm{NO}_{3}\right)$ is completely transformed in a $\mathrm{CuO}$ phase. During this heating step there is no preferential oriented grain growth. Further heat treatment at $400^{\circ} \mathrm{C}$ under $\mathrm{Ar} / \mathrm{H}_{2}$ atmosphere leads to the reduction of the copper oxide to metallic copper (Figure 6). Average grain size of the $\mathrm{Cu}$ particles is observed to be around $1 \mu \mathrm{m}$.

(b): Calcination of $\mathrm{Cu}_{2}(\mathrm{OH})_{3}\left(\mathrm{NO}_{3}\right)$ at $400^{\circ} \mathrm{C}\left(\mathrm{Ar} / \mathrm{H}_{2}\right)$

This step (b) directly follows the solvent evaporation step. In this step, metallic copper is directly formed from 


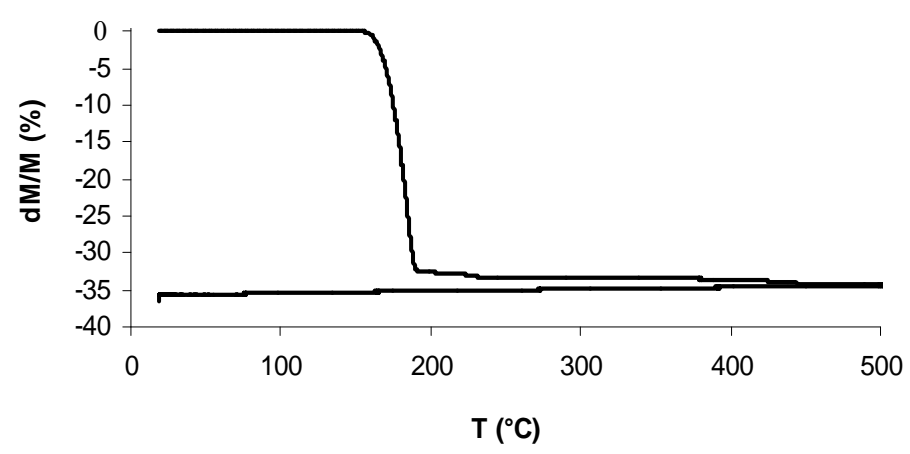

Figure 5. TGA of thermal decomposition of Cu nitrate deposited on CNF under air.

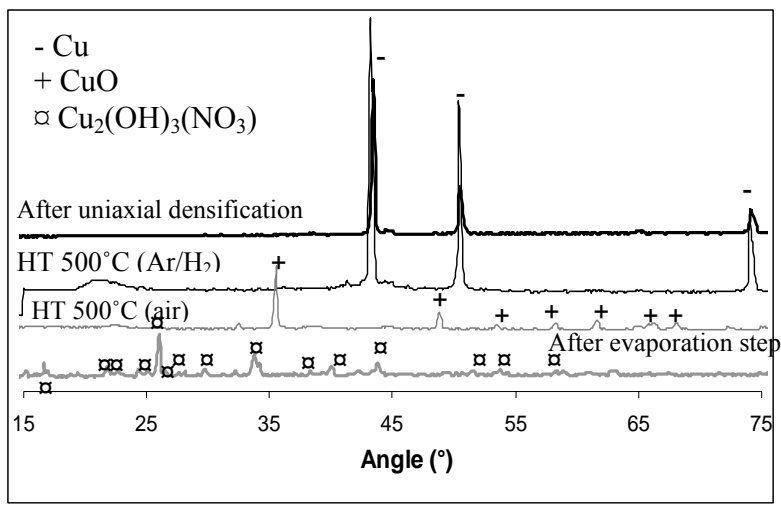

Figure 6. X-Ray diffraction patterns of the $\mathrm{Cu} / \mathrm{CNF}$ composite after different elaboration steps.

$\mathrm{Cu}_{2}(\mathrm{OH})_{3}\left(\mathrm{NO}_{3}\right)$ without $\mathrm{CuO}$ in the intermediate stage, as in step (a). SEM micrograph (Figure 7(c)) after direct heat treatment at $400^{\circ} \mathrm{C}$ under $\mathrm{Ar} / \mathrm{H}_{2}$ shows that the $\mathrm{CNF}$ are not uniformly covered with $\mathrm{Cu}$. $\mathrm{Cu}$ grains in nearspherical shape are found to be attached to CNF. Such a phenomenon was also observed by Kim et al. [14] for similar systems, and may be attributed to the melting of the nanometric grains (10 to $500 \mathrm{~nm}$ in diameter) due to the high local temperatures during heat treatment process [15].

\subsection{Thermal Characterizations}

Figure 8 shows the evolution of the thermal conductivity of the $\mathrm{Cu} / \mathrm{CNF}$ composite with the $\mathrm{CNF}$ volume percent for materials processed by salt decomposition. Three regimes can be observed: there are two horizontal regimes between 0 to 5 vol.\% and then from 5 to 10 vol. $\%$ and one decreasing regime from 10 to 20 vol. $\%$ of CNF. It should be observed that the 5 to 10 vol. $\%$ regime is above the conductivity line for that of copper. The knee occurs at about 10 vol.\%. It should be noted that our goal is to achieve conductivity higher than that of copper. Using CNF in inorganic composite systems, there is no published work today that can claim this goal. For the first time, our work shows that in the case of salt de- composition based PM, between the ranges of 5 to 10 vol. $\%, \mathrm{Cu} / \mathrm{CNF}$ composites have this distinction.

In our opinion, there are three important factors affecting the conductivity of $\mathrm{Cu} / \mathrm{CNF}$ composites that are directly due to the processing method. The first is the distribution of the reinforcement within the matrix, the second is the nature of the interfaces and the third the level of porosity (Figure 9).

In the salt decomposition coating with PM, once again based on SEM and TEM studies, good dispersion of fibers was observed. Further TEM studies (Figure 10) confirm that there is a strong interface as evidenced by lack of delamination and the presence of dislocation activity. The sharp interface is primarily achieved through a monolayer of oxygen bonding due to the functionalization of fibers. Porosity is at a very low value of about $1 \%$ and remains low up to a fiber volume fraction of $20 \%$. Finally the $\mathrm{Cu}$ grain size is micrometric that is favorable to a good heat transfer. Indeed, each grain boundary acts as a thermal resistance, so it is better from a thermal point of view to have a few micrometric grains than many nanometric grains.

\section{Summary and Conclusions}

Automotive, railway and aeronautic industries exten- 

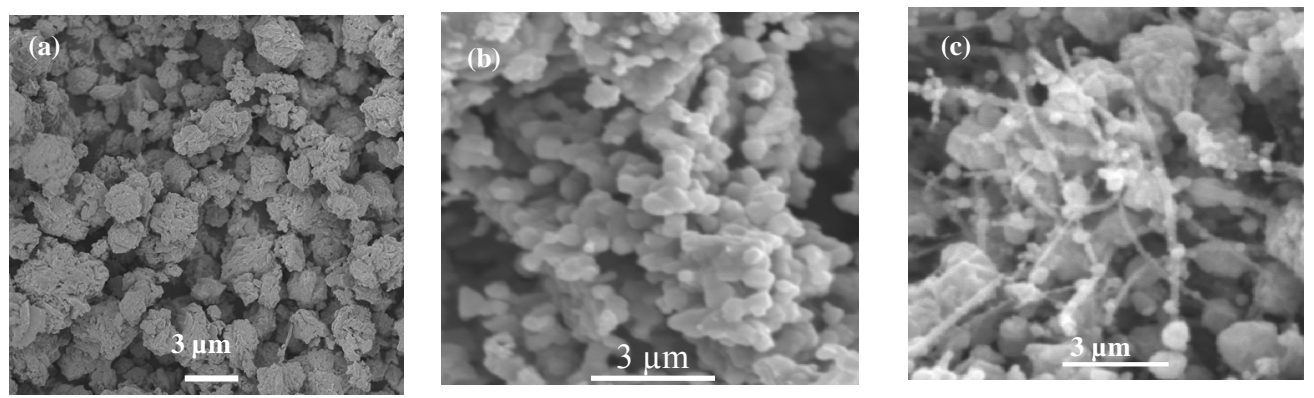

Figure 7. SE micrographs of $\mathrm{Cu} / \mathrm{CNF}$ micro-composite materials obtained by Copper Nitride salt decomposition. (a) After solvent evaporation (80 ${ }^{\circ} \mathrm{C}$, air), (b) after annealing (air $500^{\circ} \mathrm{C}+\mathrm{Ar} / \mathrm{H}_{2} 500^{\circ} \mathrm{C}$ ), (c) after annealing $\left(\mathrm{Ar} / \mathrm{H}_{2}\right.$ at $500^{\circ} \mathrm{C}$ ).

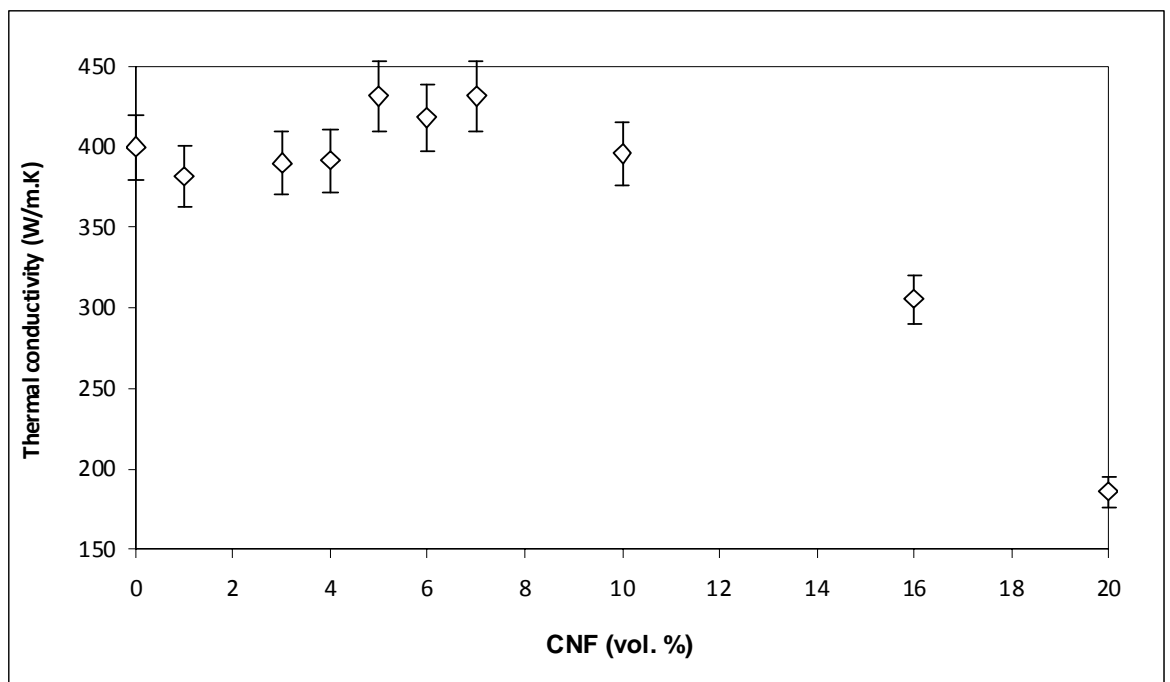

Figure 8. Evolution of the thermal conductivity with the CNF volume fraction of $\mathrm{Cu} / \mathrm{CNF}$ composite elaborated by salt decomposition and densified under $\mathrm{Ar} / \mathrm{H}_{2}$ atmosphere.

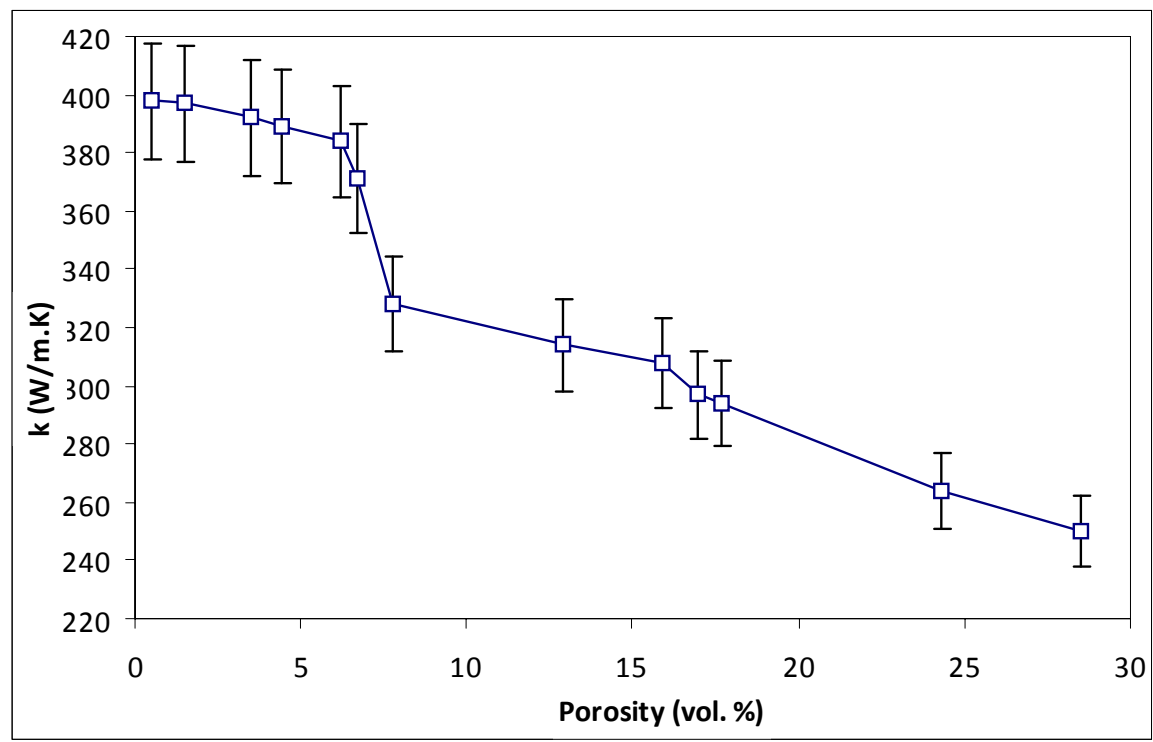

Figure 9. Evolution of the thermal conductivity with the porosity volume fraction for pure copper materials densified under Ar/ $\mathbf{H}_{2}$ atmosphere. 

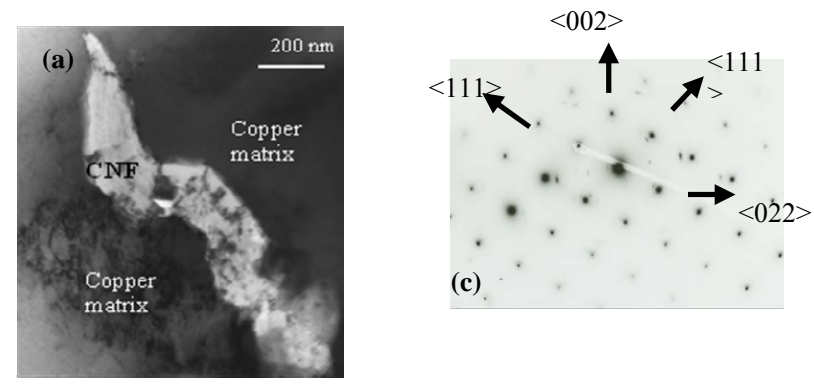

(c)

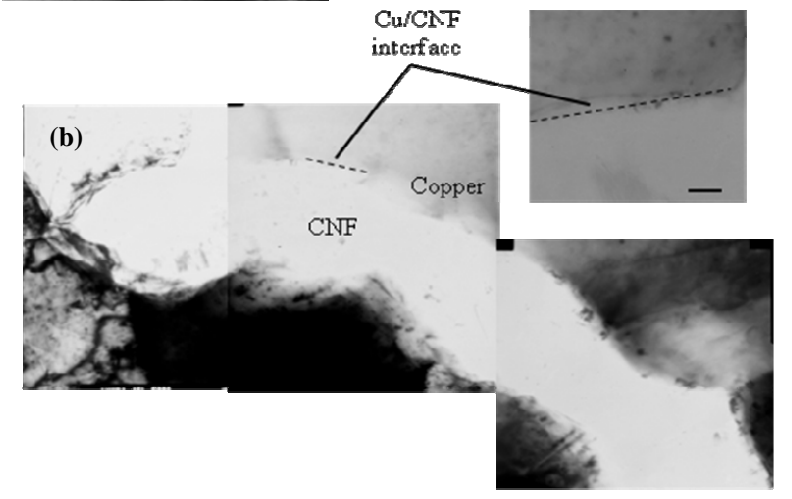

Figure 10. TEM micrographs of $\mathrm{Cu} / \mathrm{CNF}$ composite material obtained by the salt decomposition method (a) and (b) bright field, (c) diffraction pattern of the Cu matrix

sively use power electronic devices that require new materials for heat dissipation. Considering metal matrix composites, and especially copper based composites, for their high thermal conductivity values it is judicious to add carbon in the form of micro or nano fibers to adapt their thermomechanical properties. In our case, a multilayer heat sink consisting in a bulk part in $\mathrm{Cu}-\mathrm{CF}$ with a low CTE covered by a thin conductive layer of $\mathrm{Cu}-\mathrm{CNF}$ has been designed. Porosity content, dispersion of CNF and control of reinforcement-matrix interfaces are the main parameters to take into account when reaching high thermal conductivity is the objective. A novel process based on copper salt decomposition was examined for the elaboration of $\mathrm{Cu}-\mathrm{CNF}$ composite.

Detailed microstructural and thermal analysis clearly indicate that the salt decomposition method produces the desired result when the reinforcement is in the range of 5 to $10 \%$. Thus, we report for the first time an increase of the thermal conductivity of copper by incorporating carbon nanofibers. This enhancement in thermal properties combined with a multilayer design enables an improvement of reliability of power electronic systems thanks to reduced thermomechanical stresses and a reduced chip temperature during service. The properties of these copper based composite materials can be adapted by modifying volume fraction, distribution and nature (fibers, nanofibers, diamond) of carbon reinforcement. Furthermore they can be assembled in various designs to match the required specifications that make these composites versatile materials.

\section{Acknowledgements}

The authors would like to thank the CREMEM for TEM samples preparation.

\section{References}

[1] G. Korb, W. Buchgrader and T. Schubert, "Thermophysical Properties and Microstructure of Short Carbon Fibre Reinforced Cu-Matrix Composites Made by Electroless Copper Coating or Powder Metallurgical Route Respectively," Twenty-Second IEEE/CPMT International Electronics Manufacturing Technology Symposium, Berlin, 1998, pp. 98-103.

[2] J. F. Silvain, Y. L. Petitcorps and E. Sellier, "Elastic Moduli, Thermal Expansion and Microstructure of Copper-Matrix Composite Reinforced by Continuous Graphite Fibres," Composites, Vol. 25, No. 7, 1994, pp. 570574. doi:10.1016/0010-4361(94)90186-4

[3] J. F. Silvain and J. Soccart, "Structural and Thermal Properties of Hot Pressed $\mathrm{Cu} / \mathrm{C}$ Matrix Composite Materials Used for Thermal Management of High Power Electronic Devices," Materials Science Forum, Vol. 534-536, 2007, pp. 1505-1508. doi:10.4028/www.scientific.net/MSF.534-536.1505

[4] E. Flahaut, A. Peigney, Ch. Laurent, Ch. Marlière, F. Chastel and A. Rousset, "Carbon Nanotube-Metal-Oxide Nanocomposites: Microstructure, Electrical Conductivity and Mechanical Properties," Acta Materialia, Vol. 48, No. 
14, 2000, pp. 3803-3812. doi:10.1016/S1359-6454(00)00147-6

[5] K. Praksan, S. Palaniappan and S. Seshan, "Thermal Expansion Characteristics of Cast $\mathrm{Cu}$ Based Metal Matrix Composites," Composites Part A: Applied Science and Manufacturing, Vol. 28, No. 12, 1997, pp. 1019-1022. doi:10.1016/S1359-835X(97)00077-8

[6] J. Koráb, P. Stefánik, S. Kavecký, P. Sebo and G. Korb, "Thermal Expansion of Cross-Ply and Woven Carbon Fibre-Copper Matrix Composites," Composites Part A: Applied Science and Manufacturing, Vol. 33, No. 1, 2002, pp. 133-136. doi:10.1016/S1359-835X(01)00068-9

[7] J. F. Silvain, P. Richard, J. Douin, M. Lahaye and J. M. Heintz, "Electroless Coating Process of Carbon Nano Fibers by Copper Metal," Materials Science Forum, Vol. 534-536, 2007, pp. 1145-1148. doi:10.4028/www.scientific.net/MSF.534-536.1445

[8] J. F. Silvain, C. Vincent, J. M. Heintz and N. Chandra, "Novel Processing and Characterization of $\mathrm{Cu} / \mathrm{CNF}$ Nanocomposite for High Thermal Conductivity Applications," Composite Science and Technology, Vol. 69, No. 14, 2009, pp. 2474-2484. doi:10.1016/j.compscitech.2009.06.023

[9] K. T. Kim, J. Eckert, G. Liu, J. M. Park, B. K. Lim and S. H. Hong, "Influence of Embedded-Carbon Nanotubes on the Thermal Properties of Copper Matrix Nanocomposites Processed by Molecular-Level Mixing," Scripta Ma- terialia, Vol. 64, No. 2, 2011, pp.181-184. doi:10.1016/j.scriptamat.2010.09.039

[10] A. Degiovanni, “Article des Techniques de l'Ingénieur; Conductivité et diffusivité thermique des solides," R 2 850, 1994, pp. 3-15.

[11] B. Hay, J. R. Filtz and J. C.Batsale, "Article des Techniques de 1'Ingénieur; Mesure de la diffusivité thermique par la méthode flash," R 2 955, 2004, pp. 1-12.

[12] C. Vincent, "Le composite cuivre-nanofibres de carbone," ph.D. Thesis, University of Bordeaux I, 2008.

[13] I. V. Morozov, K. O. Znamenkov, Yu. M. Korenev and O. A. Shlyakhtin, "Thermal Decomposition of $\mathrm{Cu}\left(\mathrm{NO}_{3}\right)_{2} \cdot 3 \mathrm{H}_{2} \mathrm{O}$ at Reduced Pressures," Thermochimica Acta, Vol. 403, No. 2, 2003, pp. 173-179. doi:10.1016/S0040-6031(03)00057-1

[14] I. S. Kim and S. K. Lee, "Fabrication of Carbon Nanofiber/Cu Composite Powder by Electroless Plating and microstructural Evolution during Thermal Exposure," Scripta Materialia, Vol. 52, No. 10, 2005, pp. 1045-1049. doi:10.1016/j.scriptamat.2005.01.022

[15] O. A. Yeshchenko, et al., "Size-Dependent Melting of Spherical Copper Nanoparticles Embedded in a Silica Matrix," Physical Review B, Vol. 75, No. 8, 2007, ID. 085434. 